\title{
Differential Expression of Mutant and Normal Beta T3 Receptor Alleles in Kindreds with Generalized Resistance to Thyroid Hormone
}

\author{
A. J. Mixson, P. Hauser, G. Tennyson, ${ }^{\star}$ J. C. Renault, D. L. Bodenner, and B. D. Weintraub \\ Molecular and Cellular Endocrinology Branch, National Institute of Diabetes and Digestive and Kidney Diseases, National Institutes of \\ Health, Bethesda, Maryland 20892; and * Department of Medicine, Veterans Administration Medical Center, Iowa City, Iowa 52246
}

\begin{abstract}
Thyroid hormone resistance (THR) is primarily an autosomal dominant inherited disease characterized by resistance of pituitary and peripheral tissues to the action of thyroid hormone. We investigated whether the heterogeneous phenotypic features that occur not only among kindreds but also within the same kindred might be due to the expression of differing ratios of mutant and normal receptors in tissues. Using an allele-specific primer extension method, we determined the relative expression of normal and mutant mRNAs from the fibroblasts of affected and unaffected members of two kindreds with TRH: A-H and N-N. While two affected members of A-H, as expected, had nearly equal amounts of normal and mutant hTR $\beta$ mRNA, two other members had mutant mRNA levels that accounted for at least $70 \%$ of the hTR $\beta$ mRNA. Phenotypic variability within and between kindreds with generalized resistance to thyroid hormone GRTH may be due to this differential expression of the mutant and wild type mRNA. Furthermore, when several clinical parameters of THR were compared in several affected members from two kindreds with GRTH, we found that two cases in one kindred exhibited a high mutant-tonormal hTR $\beta$ ratio and had considerably more bone resistance during their development. In certain kindreds with THR, differing ratios of normal and mutant $h T R$ receptors may be age and growth related and may account for the reported attenuation of phenotypic symptoms with age. (J. Clin. Invest. 1993. 91:2296-2300.) Key words: messenger RNA • thyroid hormone receptor • phenotype $\bullet$ gene expression - thyroid hormone resistance
\end{abstract}

\section{Introduction}

Thyroid hormone resistance (THR), ${ }^{1}$ first recognized by Refetoff et al. (1), is a syndrome characterized by decreased responsiveness of target tissues to thyroid hormone. Although THR was initially separated into three disorders (generalized resistance to thyroid hormone, selective pituitary resistance, and peripheral resistance to thyroid hormone), it is now thought

Address reprint requests to Dr. Bruce D. Weintraub, Rm. 8D14, Bldg. 10, National Institutes of Health, Bethesda, MD 20892.

Received for publication 24 September 1992 and in revised form 21 December 1992.

1. Abbreviation used in this paper: THR, thyroid hormone resistance.

The Journal of Clinical Investigation, Inc.

Volume 91, May 1993, 2296-2300 that these three forms are not distinct but rather are part of a spectrum of resistance (2). Even within the same kindred, marked heterogeneity in the degree of resistance exists $(2,3)$. Most cases of thyroid hormone resistance have evidence of both pituitary and peripheral resistance and exhibit an autosomal dominant mode of inheritance. As a result, thyroid hormone resistance is phenotypically characterized by an inappropriately high thyroid-stimulating hormone (TSH) level and tissue resistance in the presence of high levels of thyroid hormone. Affected members with THR commonly have attention deficit hyperactivity disorder $(4,5)$, and language difficulty ( 3 ) and less frequently have short stature and/or delayed bone maturation $(1,3,5-7)$.

Genetic analysis of the thyroid hormone receptor has provided the basis for further understanding syndromes of thyroid hormone resistance. Two genes, $\alpha(8)$ and $\beta(9)$, each of which codes for two alternatively spliced forms of the thyroid hormone receptor, designated $\alpha 1, \alpha 2(10), \beta 1$, and $\beta 2$ (11), have been identified. The $\alpha 1, \beta 1$, and $\beta 2$ forms bind thyroid hormone, whereas the $\alpha 2$ does not. The relative roles of various forms of the receptor in mediating thyroid hormone action in different tissues is not presently known.

Initial studies by Usala et al. (12) that linked the $h \mathrm{TR} \beta$ gene to THR have led to the identification of more than 30 mutations in the $\mathrm{hTR} \beta$ gene $(3,5,13)$. These mutations are primarily clustered in two areas, the $T_{i} /$ dimerization domain of exon 9 and the L2 subdomain of exon 10 in the T3-binding region.

One of the most interesting aspects of the THR is the diversity of phenotypic expression within and among affected members of kindreds $(3,6)$. Several mechanisms might account for this phenotypic variability, such as differing levels of the hTR $\alpha 1$ receptor and $\alpha 2$, differences in the interaction with accessory proteins (14-16), and varying ratios of mutant and normal alleles. However, no data currently exist to support any of these hypotheses in tissues of patients with thyroid hormone resistance.

In this study, we investigated using an allele specific primer extension method $(17,18)$ whether the differential expression of mutant and normal mRNA levels can explain the phenotypic heterogeneity in a kindred with THR. We measured the mutant and normal mRNA levels in two kindreds: A-H, who has a $\mathrm{C}$ to $\mathrm{A}$ mutation at codon 448 , which results in a histidine for proline substitution, and kindred N-N, whose mutation in exon 9 changes a glycine to glutamate. Both of these mutations caused significant decreases in the T3 binding of the hTR $\beta$ receptor (19). While $\mathrm{N}-\mathrm{N}$ has not been tested, the A-H mutant receptor is known to have a dominant-negative effect in cells cotransfected with mutant, wild type and reporter plasmids (20). Our data suggest that varying degrees of bone resistance 
in certain patients with THR may be due at least in part to the differential expression of mutant and wild type hTR $\beta$ receptors.

\section{Methods}

Informed consent was obtained from members of kindreds $\mathrm{A}-\mathrm{H}$ and $\mathrm{N}-\mathrm{N}$ (Fig. 1) entering a peer review clinical center protocol. The clinical parameters and criteria to assess tissue responsiveness to thyroid hormone have been described elsewhere (5). Bone age delay of greater than $2 \mathrm{yr}$ assessed at two different times was necessary for diagnosing bone resistance. Bone resistance has been defined as follows in these two kindreds: + (mild), the presence of bone age delay; ++ , the presence of bone age delay and within the 5th to 10th percentile in height; +++ , the presence of bone age delay and less than the 5 th percentile of height.

Cells. Fibroblasts obtained from a skin biopsy were grown in $10 \%$ fetal calf serum and minimal essential media. Except for experiments in which the effect of passage on the mutant-to-wild-type ratio in A-H1 and A-H6 was analyzed, the fibroblasts were frozen between the 3rd and 4th passages. The cells of the patients were then thawed and grown in parallel. RNA analyses were performed on cells between the 6 th and 10th passages. When the cells reached $80 \%$ confluency in a $75 \mathrm{~cm}^{2}$ flask, they were washed with phosphate buffer saline. After washing the fibroblasts with phosphate buffer saline, the RNA was processed by the RNAzol protocol (Cinna Co., Friendswood, TX).

Preparation of $c D N A$ from fibroblasts. $1 \mu \mathrm{g}$ of total RNA was reverse transcribed with Avian reverse transcriptase using primer A (ATGAGAATGAATCCAGTCAG; 1692-1673) for $1 \mathrm{~h}$. The single stranded cDNA was then amplified with primers A and K (GAGCTGCCATGTGAAGACCAG; 1168-1188). The product was then reamplified using internal primers H(CAGTCTAATCCTCGAACAC; 1675-1656) and N(GTCCCTTCGCGCTGCTGTG; 1224-1242). The product was analyzed on a 3\% agarose gel (Nusieve; FMC Corp, Rockland, ME) and then purified with prep-a-gene (Bio Rad Labs, Hercules, CA). Amplification and reamplification occurred during 35 and 26 cycles, respectively $\left(1 \mathrm{~min}, 94^{\circ} \mathrm{C} ; 1 \mathrm{~min}, 60^{\circ} \mathrm{C}\right.$; and 1 $\min , 72^{\circ} \mathrm{C}$ ).

Allele specific primer extension method. We chose the allele specific primer extension method because of its ease and reliability. We followed the protocol of Driscoll et al. (17) and Tennyson et al. (18). In brief, $3 \mu \mathrm{l}$ of amplified cDNA ( $50 \mathrm{ng}$ ), $2 \mu \mathrm{l}$ of $5 \mathrm{X}$ annealing buffer (United States Biochem. Corp., Cleveland, $\mathrm{OH}$ ) and $1 \mu \mathrm{l}$ end-labeled primer (GAATGCCCCACAGAACTCTT; 1617-1637) specific for both mutant and wild-type cDNAs were denatured and reannealed slowly. After the temperature cooled to $42^{\circ} \mathrm{C}$, sequenase 2.0 (United States Biochem. Corp.) and dT, dC, dG at a final concentration of 0.1 $\mathrm{mM}$ and $0.25 \mathrm{mM}$ ddA were added for $10 \mathrm{~min}$ before formamide was added. With the mutant allele of kindred $\mathrm{A}-\mathrm{H}$, the primer is extended just 4 additional bases, whereas with the wild-type cDNA, the primer is extended 18 bases. The primer, wild type, and mutant fragments were then separated on a $17 \%$ denaturing acrylamide gel. The mutant and

A

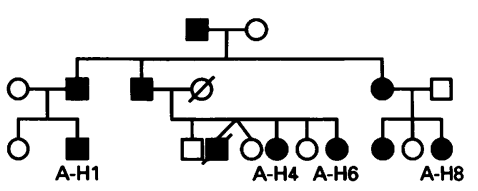

B

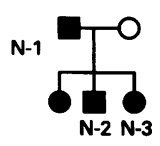

Figure 1. Pedigrees of kindreds $\mathrm{A}-\mathrm{H}$ and $\mathrm{N}-\mathrm{N}$.
A.

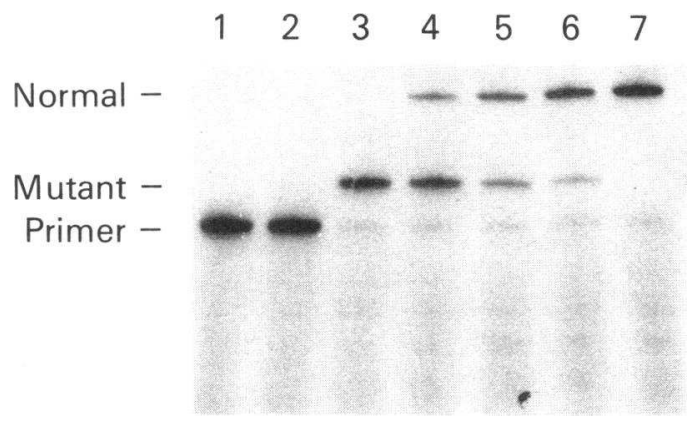

B.

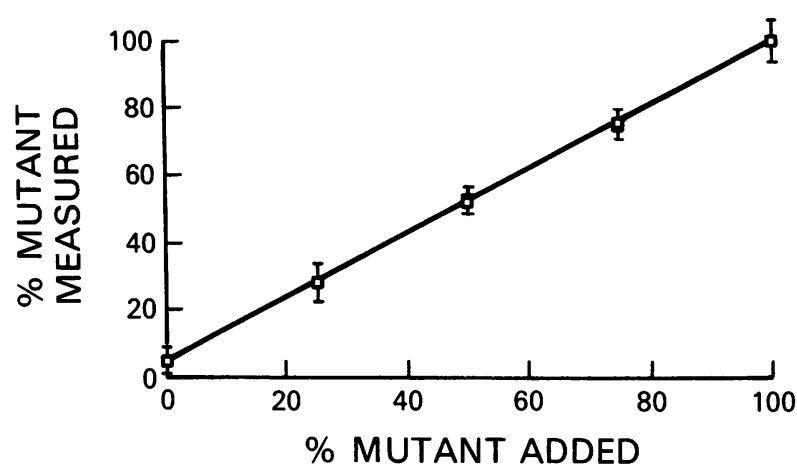

Figure 2. Quantitation of different amounts of mutant and wild-type plasmid DNA by the primer extension method. $(A)$ The results of the primer extension method after mixing and amplifying different ratios of wild-type and mutant plasmids. Lanes 1 and 2 represent controls in which no DNA was added, whereas the percentages of the A-H mutant plasmid relative to wild-type corresponding to lanes 3 through 7 were as follows: lane 3,100\%; lane 4,75\%; lane 5, 50\%; lane $6,25 \%$; and lane $7,0 \%$. $(B)$ The relationship between the percentage of mutant plasmid added and the percentage of mutant CDNA measured. Each point represents the mean and standard deviation of four determinations from two separate experiments. The mutant and wild-type bands were quantitated with a Beta scanner (AMBIS Inc.).

wild type bands were quantitated by a Beta scanner (AMBIS Inc. San Diego, CA).

\section{Results}

We investigated whether the primer extension method could reliably quantitate different amounts of mutant and wild type plasmid DNA after mixing and amplifying different ratios. Fig. 2 reveals that the allele specific primer extension method is extremely sensitive and accurate. Fig. $2 B$ shows the relationship between the relative ratio of mutant and the wild-type plasmid added. The correlation coefficient is 0.99 .

After determining that allele specific primer extension was a precise and accurate method and could detect small differences in the mutant and wild-type DNA, we initially isolated RNA from three members of the A-H kindred. The one unaffected member ( $\mathrm{A}-\mathrm{H} 3)$, as expected, had only wild type cDNA while the affected members (A-H1, A-H6) had marked differences in the relative expression of mutant and normal mRNA that were reproducible in several determinations (Fig. 3). Whereas 12-yr-old A-H1 had mRNA levels of mutant and nor- 
A-H1 A-H6 A-H3

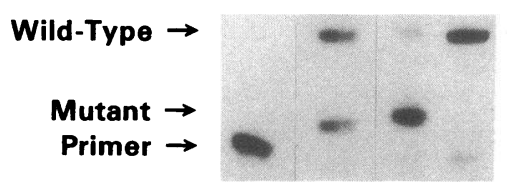

Figure 3. Relative expression of mutant and wild-type hTR $\beta$ mRNA in fibroblasts. The first lane represents primer alone, lane $2 \mathrm{~A}-\mathrm{H} 1$, the affected proband, in lane 3 , an affected case A-H6 and the fourth lane represents the unaffected case A-H3.

mal hTR $\beta$ mRNAs that were nearly equal, 5-yr-old A-H6 had a mutant mRNA level that accounted for $84 \%$ of the hTR $\beta$ mRNA. Furthermore, these results were not dependent on the primers since different oligonucleotides used for reverse transcription and amplification gave similar percentages for these three members, and A-H1 and A-H6 who had the same mutation gave reproducible but different results.

Of the several clinical parameters that were used to stratify patients with generalized resistance to thyroid hormone, only bone resistance was significantly greater in A-H6 compared with A-H1 at the time the biopsy was performed (Tables I, II). The 5-yr-old A-H6's height was less than the 5th percentile whereas the 12-yr-old A-H1 was in the 40th percentile.

In the six years since we had performed the initial skin biopsy on A-H6, her growth curve had changed significantly from less than the 5th percentile to the 25th percentile (Fig. 4). There had been no significant illness, nutritional deficiencies, nor any evidence of precocious puberty to account for the alteration in A-H6's growth curve. Furthermore, since her thyroid hormone therapy was begun two years prior to her growth curve acceleration, it is doubtful that it had a significant role in her growth curve changing from the 5th to 25 th percentile. To investigate whether this change might be associated with a relative decrease in the mutant/normal mRNA ratio and presumably the protein levels, we performed a second biopsy on A-H6 when she was $11 \mathrm{yr}$ old. Her mutant-to-normal ratio had de-

Table I. Clinical Parameters of $A-H 1$ and A-H6

\begin{tabular}{lccc}
\hline \multicolumn{1}{c}{ Parameters } & A-H1 & A-H6 & Normal values \\
\hline Age, year & $11^{5} / 12$ & 5 & NA \\
T4, $\mu$ g/dl & 29.8 & - & $5-12$ \\
FT4, ng/dl & 5.6 & 2.8 & $1-1.9$ \\
T3, ng/dl & 352 & 361 & $111-199$ \\
TSH, mU/liter & 2 & 3.6 & $0-3.9$ \\
Height & 40 & $<5$ & 5 to 95 \\
Bone age, \pm SD & $<2$ & $>2$ & \pm 2 \\
BMR, percent & -46 & -22 & -20 to +20 \\
Resting pulse & 72 & 116 & $70-85$ \\
Cholesterol, mg/dl & 162 & 186 & $<200$ \\
FSIQ & 72 & 74 & $>80$ \\
ADHD & + & + & -
\end{tabular}

After comparing several clinical parameters to determine whether the elevated mutant mRNA of A-H6 correlated with more resistance in various peripheral tissues, only bone resistance was markedly greater in A-H6 compared with A-H1. FSIQ, full scale IQ; ADHD, attention deficit hyperactivity disorder; NA, not applicable.

Table II. Relationship of Age, Bone Resistance, and Percent Mutant hTR $\beta$ Gene

\begin{tabular}{lllll}
\hline Case & Age & Height & Delay & \% Mutant
\end{tabular}

Kindred A-H

$\begin{array}{lrrccc}\text { A-H6 } & 5 & <5 & + & 84 \pm 6 & 6 \\ \text { A-H6 } & 11 & 25 & +/- & 67 \pm 7 & 4 \\ \text { A-H4 } & 4 & <5 & + & \text { N.D. } & \\ \text { A-H4 } & 13 & 25 & - & 69 \pm 4 & 3 \\ \text { A-H1 } & 11 & 40 & +/- & 58 \pm 6 & 6 \\ \text { A-H1 } & 17 & 50 & - & 54 & 3 \\ \text { A-H8 } & 3 & 10 & - & 52 & 3\end{array}$

Kindred N-N

$\begin{array}{rrrrrr}\text { N-N2 } & 15 & >25 & - & 56 & 2 \\ \text { N-N3 } & 11 & 25 & - & 57 & 2\end{array}$

This table shows the relationship between bone resistance and percent mutant expressed in fibroblasts of affected patients. Percent mutant is expressed as the mean and standard deviation of several determinations. $N$ represents the number of times the percent mutant was determined from total RNA. Bone delay of greater than 2 yr was necessary for diagnosing bone resistance. ND, not determined.

creased to $67 \%$ whereas A-H1's mutant-to-normal ratio was still nearly equal (Table II). We also analyzed whether the fibroblast passage of A-H6 resulted in a change in the ratio of $\mathrm{hTR} \beta$ gene, and found that passages 1 and 6 displayed similar mutant-to-normal ratios (Fig. 5).

Since growth appeared to correlate with differing ratios of $\mathrm{hTR} \beta$ gene and presumably the hTR $\beta$ receptor protein, we measured the hTR $\beta$ mRNA ratios in an additional two affected children of the A-H kindred, A-H4 and A-H8. 3-yr-old A-H8 had a relative mutant hTR $\beta$ expression of $52 \%$ and never had any evidence of bone age delay (Fig. 6 ). In contrast, the relative expression of the mutant hTR $\beta$ of the 13 -yr-old A-H4 was $69 \%$ (Fig. 6). Similar to A-H6, A-H4 at an early age was less than the 5th percentile in height and had a significant bone age delay, but when she was $13 \mathrm{yr}$ old, her height was slightly greater than the 25th percentile. Furthermore, members of kindred $\mathrm{N}-\mathrm{N}$ who varied little from the expected $50 \%$ of the mutant and wild-type mRNA did not have any bone resistance.

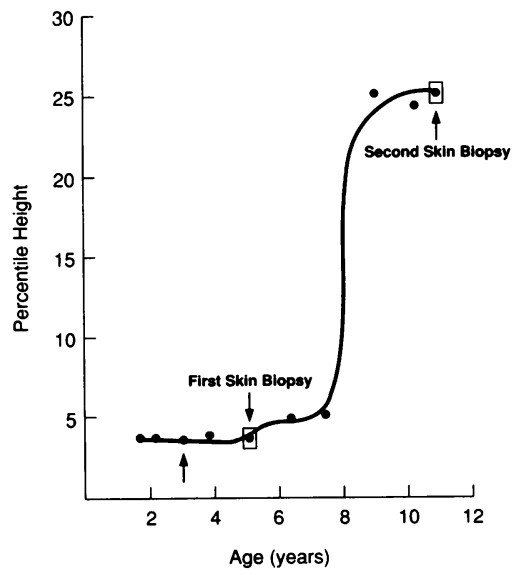

Figure 4. Growth curve of A-H6. After the initial skin biopsy, A-H6 growth curve had changed significantly from less than the 5th percentile to the 25 th percentile. Arrow indicates when thyroid hormone therapy was initiated. 


\section{Discussion}

The clinical presentation of THR kindreds is quite varied. Although attention deficit hyperactivity disorder is quite common (4), language ( 3 ) and bone resistance $(3,5)$ are less commonly seen. In fact, of the 14 kindreds in which we identified a mutation, only four have evidence of bone resistance. Unlike the kindred ( first described by Refetoff et al.) who had stippled epiphyses, none of our kindreds exhibited this abnormality. Our kindreds had either bone age delay and/or short stature. Of the four kindreds $(3,5-7)$ with bone resistance, kindred A- $\mathrm{H}$ was particularly interesting in that several members manifested varying degrees of bone resistance.

In this study, we found marked differential expression of mutant and normal mRNA levels in kindred $\mathrm{A}-\mathrm{H}$, and this may account for the differing degrees of bone resistance seen in members within these kindreds. The approximately $20 \%$ reduction in the mutant $\mathrm{hTR} \beta$ mRNA, and presumably the mutant receptor protein, of A-H6 was associated with a marked increase in her height; this amount of mRNA diminution is probably significant in this autosomal dominant disease. Although a correlation was seen between bone resistance and the percent mutant hTR $\beta$ gene expressed in fibroblasts (Table II), the etiology and molecular mechanisms underlying this relationship remain unclear. Since our clinical parameters for thyroid hormone resistance reflect only a limited number of tissues, it is certainly possible that altered ratios of wild-type and mutant hTR $\beta$ mRNA may be occurring in several tissues not measured by our present clinical parameters. Alternatively, even in tissues where the degree of resistance was measured with clinical parameters, there may be other factors that influence the resistance phenotype of these tissues. Some of the factors that could influence phenotypic features besides an altered ratio are differences in the thyroid hormone alpha and beta receptor levels or $\operatorname{RXR} \beta$ levels, but these remain to be elucidated.

The mechanism resulting in the relative increase of the mutant allele in the coding region is unknown. Epigenetic factors $(21,22)$ are known to increase or decrease the transcriptional activity of a particular allele and may play a role in the increased transcriptional activity of the mutant allele. Although GRTH is an autosomal dominant disease with the affected allele identified in the two presently studied kindreds, this does not preclude the possibility that the wild-type allelic mRNA level is decreased. Variably expressed wild-type alleles have been found to have significant effects when combined with an affected allele. For instance, Kadowaki et al. (23) report that in one case of leprechaunism, an autosomal recessive disease associated with extreme insulin resistance, a maternally inherited

\footnotetext{
$\begin{array}{llllllll}1 & 2 & 3 & 4 & 5 & 6 & 7 & \text { Figure 5. The relation- }\end{array}$ ship of age to hTR $\beta$ mutant mRNA levels in patient A-H6. Lane 1
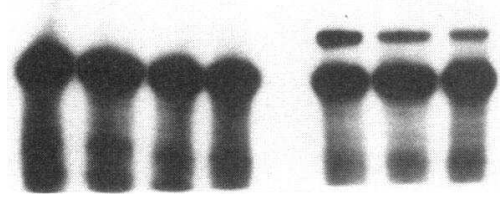
represents primer alone, 2 through 4 represent controls without reverse transcriptase added (lane 2, A-H6, first biopsy; lane $3 \mathrm{~A}-\mathrm{H} 6$, first passage, second

biopsy; lane 4 A-H6, sixth passage, second biopsy). Lanes 5 through 7 correspond to 2 through 4 except reverse transciptase was added.
}

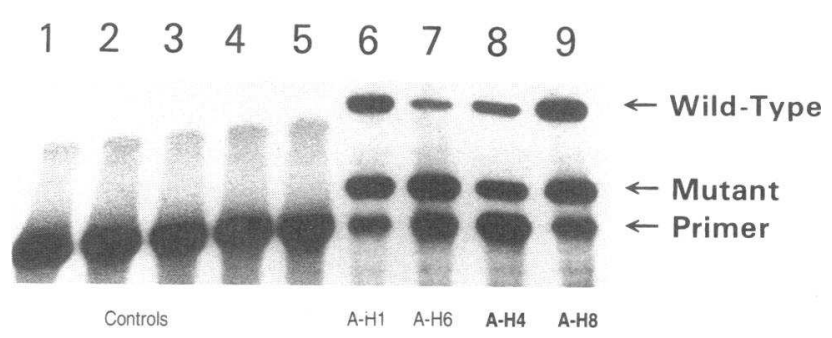

Figure 6. Expression of mutant hTR $\beta$ of A-H kindred. The first lane represents primer alone, lanes 2 through 5 correspond to lanes 6 through 9 except that transcriptase was not added. Lane 6 examines A-H1, first biopsy; lane 7, A-H6; lane 8, A-H4; lane 9, A-H8.

"normal" allele is profoundly decreased. Although a mutation has not yet been located in the maternal insulin gene, it is very likely.

Alternatively, a preferential increase of the mutant allelic mRNA may occur as a result of increased stability of the mutant mRNA. Mutations in the coding region are known to affect the stability of the mRNA. Both c-fos (24) and $\beta$ tubulin (25) have areas within the coding region that stabilize these genes. Interestingly, Cohen et al. (26) reported that a mutation in the intron of the oncogene, h-ras, increased its expression by 10 -fold. The mechanism causing this increase is also unknown. Perhaps the mutation in kindred A-H increases stability by altering a region that is recognized by a specific nuclease. Because varying levels of mutant and normal $h \mathrm{TR} \beta$ mRNA are present within members of kindred $\mathrm{A}-\mathrm{H}$, this mutation would be necessary but not sufficient for these heterogeneous levels of mRNA. A second factor present to differing degrees in affected members of A-H would be necessary to destabilize the normal allele but not the affected allele.

Diversity of phenotypic expression between affected members of kindreds is one of the most interesting aspects of this disease. In addition to the differential expression of the mutant and wild-type alleles, other mechanisms may account for the heterogeneity of clinical manifestations. This diversity of phenotypic expression may reflect varying levels of $h T R \alpha$ in these tissues. Alternatively, transcriptional factors such as RXR that modulate the action of the $\operatorname{hTR} \beta(14,15)$ may explain this diversity. We are presently studying the role of these accessory factors in the phenotypic expression of THR.

\section{References}

1. Refetoff, S., L. T. DeWind, and L. DeGroot. 1967. Familial syndrome combining deaf-mutism, stippled epiphyses, goiter, and abnormally high PBI: possible target organ refractoriness to thyroid hormone. J. Clin. Endocrinol. \& Metab. 27:279-294.

2. Mixson, A. J., J. C. Renault, S. Ransom, and B. D. Weintraub. 1993. Identification of a novel mutation in the gene encoding the $\beta$-triiodothyronine receptor in a patient with apparent selective pituitary resistance to thyroid hormone. Clin. Endocrinol. In press.

3. Mixson, A. J., R. Parilla, S. C. Ransom, E. A. Wiggs, J. H. McClaskey, P. H. Hauser, and B. D. Weintraub. 1993. Correlations of language abnormalities with localization of mutations in the $\beta$-thyroid hormone: Identification of four new mutations. J. Clin. Endocrinol. \& Metab. 75:1039-1045.

4. Hauser, P., A. J. Zametkin, P. Martinez, B. Vitiello, J. Matochik, E. Wiggs, A. J. Mixson, and B. D. Weintraub. Attention-deficit hyperactivity disorder and altered cerebral glucose metabolism in 18 kindreds with generalized resistance to thyroid hormone. $N$. Engl. J. Med. In press.

5. Parrilla, R., A. J. Mixson, J. McPherson, J. H. McClaskey, and B. D. Weintraub. 1991. Characterization of seven novel mutations of the c-erbAB gene in unrelated kindreds with generalized thyroid hormone resistance. Evidence for two "hot spot" regions of the ligand binding domain. J. Clin. Invest. 88:2123-30.

6. Magner, J. A., P. Petrick, M. Menezes-Ferreira, and B. D. Weintraub. 1986. 
Familial generalized resistance to thyroid hormones: report of three kindreds and correlation of patterns of affected tissues with the binding of [1125]triiodothyronine to fibroblast nuclei. J. Endocrinol. Invest. 9:459-469.

7. Usala, S. J., G. E. Tennyson, A. E. Bale, R. W. Lash, N. Gesundheit, D. Accili, P. Hauser, and B. D. Weintraub. 1990. A base mutation of the c-erbA thyroid hormone receptor in a kindred with generalized thyroid hormone resistance. J. Clin. Invest. 85:93-100.

8. Sheer, D., D. M. Sheppard, M. LeBeau, J. D. Rowley, D. San Roman, and E. Solomon. 1985. Localization to the c-erbAl immediately proximal to the acute promyelocytic leukemia break-point on chromosome 17. Ann. Hum. Genet. 49:167-171.

9. Drabkin, H., F. T. Kao, J. Hartz, I. Hart, A. Gazdar, C. Weinberger, R. Evans, and M. Gerber. 1988. Localization of human ERBA2 to the 3p22 $\rightarrow$ 3 p24.1 region of chromosome 3 and variable deletion in small cell lung cancer. Proc. Natl. Acad. Sci. USA. 85:9258-9262.

10. Metsuhashi, T., G. E. Tennyson, and V. M. Nikodem. 1988. Alternative splicing generates messages encoding for c-erbA proteins that do not bind thyroid hormone. Proc. Natl. Acad. Sci. USA. 85:5804-5808.

11. Hodin, R. A., M. A. Lazar, B. E. Wintman, D. S. Darling, R. J. Koenig, R. Larsen, D. Moore, and W. W. Chin. 1989. Identification of a thyroid hormone receptor that is pituitary-specific. Science (Wash. DC). 244:76-78.

12. Usala, S. J., A. E. Bale, N. Gesundheidt, C. Weinberger, R. W. Lash, F. E. Wondisford, O. W. McBride, and B. D. Weintraub. 1988. Tight linkage between the syndrome of generalized thyroid hormone resistance and the human c-erbA gene. Mol. Endocrinol. 2:893-901.

13. Takeda, K., R. E. Weiss, and S. Refetoff. 1992. Rapid localization of mutations in the thyroid hormone receptor- $\beta$-gene by denaturing gradient gel electrophoresis in 18 families with thyroid hormone resistance. J. Clin. Endocrinol. \& Metab. 4:7122-7129.

14. Yu, V. C., C. Delsert, B. Andersen, J. M. Hollaway, O. V. Devary, A. M. Naar, S. Y. Kim, J-M, Boutin, C. K. Glass, and M. G. Rosenfeld. 1992. RXRB: A coregulator that enhances binding of retinoic acid, thyroid hormone, and vitamin D receptors to their cognate response elements. Cell. 67:1251-1266.

15. Meier-Heusler, S., C. A. Meier, P. Muchmore, S.-Y. Cheng, and B. D. Weintraub. 1992. Mutant $\beta 1$ T3-receptors from kindreds with generalized resis- tance to thyroid hormone: interactions with RXR $\beta$ and DNA. Thyroid. 2:S-99. (Abstr.)

16. Burnside, J., D. S. Darling, and W. W. Chin. 1990. A nuclear factor that enhances thyroid hormone receptors to thyroid hormone response elements. $J$. Biol. Chem. 265:2500-2504.

17. Driscoll, D. M., J. K. Wynne, S. C. Wallis, and J. Scott. 1989. An in vitro system for the editing of apolipoprotein B mRNA. Cell. 58:519-525.

18. Tennyson, G. E., C. A. Sabatos, D. Higuchi, N. Meglin, and H. B. Brewer, Jr. 1989. Characterization of apolipoprotein B mRNAs encoding higher and lower molecular weight isoprotein in rat liver and intestine. Proc. Natl. Acad. Sci. USA. 86:500-504.

19. Usala, S. J., F. E. Wondisford, T. L. Watson, J. B. Menke, and B. D. Weintraub. 1990. Thyroid hormone and DNA binding properties of a mutant c-erbA $\beta$ receptor associated with generalized thyroid hormone resistance. Biochem. Biophys. Res. Commun. 171:575-580.

20. Krishna, V. K. K., T. Nagaya, L. D. Madison, S. Datta, A. Rentoumis, and J. L. Jameson. 1991. Thyroid hormone resistance syndrome. Inhibition of normal receptor function by mutant hormone receptors. J. Clin. Invest. 87:19771984.

21. Reik, W. 1989. Genomic imprinting and genetic disorders in man. Hum. Gen. Dis. 5:331-336.

22. Adams, R. 1990. DNA methylation. Biochem. J. 265:309-320.

23. Kadowaki, T., H. Kadowaki, and S. Taylor. 1990. A nonsense mutation causing decreased levels of insulin receptor mRNA: Detection by a simplified technique for direct sequencing of genomic DNA amplified by the polymerase chain reaction. Proc. Natl. Acad. Sci. USA. 87:658-662.

24. Shyu, A. B., M. E. Greenberg, and J. G. Belasco. 1989. The c-fos transcript is targeted for rapid decay by two distinct mRNA degradation pathways. Genes \& Dev. 3:60-72.

25. Gay, D. A., T. J. Yen, J. T. Lau, and D. W. Cleveland. 1987. Sequences that confer $\beta$-tubulin autoregulation through modulated mRNA stability reside within exon 1 of the $\beta$-tubulin mRNA. Cell. 50:671-679.

26. Cohen, J. B., and A. D. Levinson. 1988. A point mutation in the last intron responsible for increased expression and transforming activity of the c-Haras oncogene. Nature (Lond.). 334:119-124. 